\title{
Variability of the plateau response to methacholine in subjects without respiratory
} symptoms

\author{
M D Lougheed, G Pearce-Pinto, N H de Klerk, G Ryan, A W Musk, A James
}

\begin{abstract}
Background-Interpretation of measurements of limited maximal airway narrowing, or plateau response, requires knowledge of its variability within subjects and between methods.

Methods-The repeatability of the plateau response to inhaled methacholine with a dosimeter (D) method (maximal dose $210 \mu \mathrm{mol}$ ) and a tidal breathing (T) method (730 $\mu \mathrm{mol})$, and the agreement of the two methods, were measured in 16 subjects with mild or no asthma. Two tests by each method $(\mathrm{D} 1, \mathrm{D} 2, \mathrm{~T} 1, \mathrm{~T} 2)$ were performed in random order over four consecutive days, with a third dosimeter (D3) test one week later. The dose producing a decrease in forced expiratory volume in one second $\left(F E V_{1}\right)$ of $10 \%\left(P_{10}\right)$ and the plateau were calculated from each dose-response curve.
\end{abstract}

Results-A plateau was reached in all five tests in 12 subjects and in all tests except D3 in 14 subjects. $P_{10}$ was inversely related to the plateau $(r=-0.95$ for $D, r=-0.77$ for $T)$. The $95 \%$ ranges for differences between two determinations of the plateau in a subject were $\pm 11.9 \%$ (change in FEV F $_{1}, \pm 19 \cdot 2 \%$, and $\pm 20 \cdot 3 \%$, estimated from D1-2 and 1-3, and T1-2 tests, respectively. From the same tests the $95 \%$ ranges for the difference of a single determination from an individual's true mean value were $\pm 8 \cdot 3 \%, \pm 13 \cdot 6 \%$, and $\pm 14 \cdot 3 \%$. The limits of agreement between methods indicated that $95 \%$ of the measurements of the plateau by tidal breathing ranged from $15 \cdot 2 \%$ below to $13 \cdot 3 \%$ above those obtained by dosimeter. There was no significant bias between methods. Tachyphylaxis over 24 hours occurred with $\mathbf{P D}_{10}$ but not with the plateau response.

Conclusions-The plateau response is a subject characteristic which is independent of the method of inhalation challenge testing. Repeatability of the plateau is low in this group of subjects with low airway responsiveness.

(Thorax 1993;48:512-517)

Bronchial responsiveness is often assessed by measuring the changes in lung function induced by inhaling increasing doses of bronchoconstricting agents such as methacholine. The two most commonly used methods of inhalation challenge testing are the tidal breathing method $^{12}$ and the dosimeter method. ${ }^{34}$ The position ${ }^{5}$ and shape $^{6}$ of the dose-response curves obtained differ in patients with asthma from those in normal subjects. In patients with asthma the curve is shifted to the left, reflecting increased airway sensitivity. ${ }^{5}$ This is commonly expressed as the provocative concentration $\left(\mathrm{PC}_{20}\right)^{1}$ or dose $\left(\mathrm{PD}_{20}\right)^{3}$ causing a $20 \%$ fall in forced expiratory volume in one second $\left(\mathrm{FEV}_{1}\right)$.

It has been noted that the dose-response curves are sigmoid in shape and reach a maximum response (plateau) in individuals with normal or mildly increased airway sensitivity. ${ }^{67}$ Individuals with moderate or severe asthma fail to reach a plateau despite a fall in $\mathrm{FEV}_{1}$ of up to $60 \% .^{6}$ It has been proposed that the presence of a plateau response indicates a limit to the degree to which airways can narrow, while moderate to severe asthma is characterised by the absence of such a limitation to maximal airway narrowing. ${ }^{67}$

The possibility that the level of the plateau response is related to the method of inhalation challenge has not been fully investigated. If the plateau is a stable characteristic of an individual, it should be similar with different methods of testing. The aims of this study were to assess the repeatability of the plateau response in subjects with no asthma or with mild asthma by a dosimeter method and a tidal breathing method, and to assess the agreement between the two methods.

\section{Methods}

SUBJECTS

Sixteen adult volunteers from the hospital and laboratory staff took part in the study (table 1). Subject no. 6 had had intermittent wheeze and chest tightness within the previous month and was taking salbutamol as required and regular beclomethasone but did not use salbutamol within six hours of testing on any of the test days. Two subjects had a previous history of asthma but were free of symptoms at the time of the study and were not taking medication. Seven subjects had a history of hay fever although none had any respiratory symptoms during the period of the study. Atopic state was not tested and no subject had an upper respiratory infection. All 
Table 1 Subject characteristics

\begin{tabular}{|c|c|c|c|c|c|c|c|c|}
\hline \multirow{2}{*}{$\begin{array}{l}\text { Subject } \\
\text { no. }\end{array}$} & \multirow{2}{*}{ Sex } & \multirow{2}{*}{$\begin{array}{c}\text { Age } \\
(y)\end{array}$} & \multirow{2}{*}{$\begin{array}{l}\text { Height } \\
(\mathrm{cm})\end{array}$} & \multicolumn{3}{|c|}{ History of: } & \multicolumn{2}{|c|}{ Initial $F E V_{1}$} \\
\hline & & & & Asthma & Wheeze & Hay fever & (l) & (\%pred) \\
\hline 1 & $\mathbf{M}$ & 38 & 165 & $\mathrm{~N}$ & $\mathbf{N}$ & $\mathrm{Y}$ & 3.67 & 102 \\
\hline 2 & $\mathbf{M}$ & 34 & 180 & $\mathrm{~N}$ & $\mathrm{~N}$ & $\mathrm{Y}$ & $3 \cdot 35$ & 81 \\
\hline 3 & $F$ & 28 & 167 & $\mathrm{~N}$ & $\mathrm{Y}$ & $\mathbf{N}$ & $2 \cdot 75$ & 85 \\
\hline 4 & $\mathrm{~F}$ & 25 & 160 & $\mathrm{~N}$ & $\mathbf{N}$ & $\mathbf{N}$ & 3.02 & 96 \\
\hline 5 & $\mathbf{M}$ & 27 & 185 & $\mathbf{N}$ & $\mathbf{N}$ & $\mathbf{Y}$ & $4 \cdot 12$ & 90 \\
\hline 6 & $\mathbf{M}$ & 30 & 178 & $\mathbf{Y}$ & $\mathrm{Y}$ & $\mathbf{Y}$ & 3.60 & 86 \\
\hline 7 & $\mathbf{F}$ & 28 & 165 & $\mathrm{Y}$ & $\mathbf{Y}$ & $\mathrm{Y}$ & $2 \cdot 83$ & 87 \\
\hline 8 & $\mathbf{F}$ & 33 & 160 & $\mathbf{N}$ & $\mathrm{N}$ & $\mathbf{N}$ & $2 \cdot 74$ & 94 \\
\hline 9 & $\mathrm{M}$ & 45 & 183 & $\mathrm{~N}$ & $\mathrm{~N}$ & $\mathrm{~N}$ & $4 \cdot 40$ & 108 \\
\hline 10 & M & 45 & 165 & $\mathrm{Y}$ & $\mathrm{N}$ & $\mathrm{Y}$ & $2 \cdot 89$ & 86 \\
\hline 11 & $\mathbf{F}$ & 21 & 160 & $\mathbf{N}$ & $\mathrm{N}$ & $\mathbf{N}$ & $2 \cdot 46$ & 78 \\
\hline 12 & $\mathbf{F}$ & 28 & 167 & $\mathrm{~N}$ & $\mathrm{~N}$ & $\mathbf{N}$ & $2 \cdot 54$ & 78 \\
\hline 13 & $\mathbf{F}$ & 27 & 178 & $\mathbf{N}$ & $\mathbf{N}$ & $\mathbf{N}$ & 4.05 & 112 \\
\hline 14 & $M$ & 22 & 180 & $\mathbf{N}$ & $\mathrm{N}$ & $\mathrm{N}$ & 3.51 & 80 \\
\hline 15 & $\mathrm{M}$ & 38 & 184 & $\mathrm{~N}$ & $\mathrm{~N}$ & $\mathrm{Y}$ & 3.68 & 85 \\
\hline 16 & $\mathbf{M}$ & 27 & 168 & $\mathrm{~N}$ & $\mathrm{~N}$ & $\mathbf{N}$ & $4 \cdot 01$ & 100 \\
\hline \multirow{2}{*}{\multicolumn{2}{|c|}{$\begin{array}{l}\text { Mean } \\
\text { Range }\end{array}$}} & 31 & 172 & & & & & 91 \\
\hline & & $21-45$ & $160-184$ & & & & & $78-112$ \\
\hline
\end{tabular}

$\mathrm{FEV}_{1}$-forced expiratory volume in one second.

subjects were either lifelong non-smokers $(n=11)$ or ex-smokers $(n=5)$ and had an initial $\mathrm{FEV}_{1}$ greater than $78 \%$ of the predicted value ${ }^{8}$ at the time of the study.

\section{STUDY DESIGN}

Subjects were questioned about smoking history, history of wheeze, hay fever or doctor diagnosed asthma, and current medications. Each subject performed two dosimeter and two tidal breathing inhalation challenges, in random order, over four consecutive days. To test the repeatability of the dosimeter method over a longer interval a third test was performed about one week later. All five tests were performed at the same time of day.

\section{Dosimeter method}

Solutions were delivered from two DeVilbiss \#646 nebulisers driven by an air compressor (Dynavac, Sydney, Australia). Nebulisation time was 0.6 seconds. The mean (SD) output of the nebulisers was determined by weighing them before and after 10 nebulisations on 10 occasions, without a subject. The mean (SD) outputs were $0.014(0.001) \mathrm{ml}$ and $0.016(0.002) \mathrm{ml}$ per nebulisation of 0.6 seconds. The same nebuliser was used for all solutions in a given test. Using a noseclip and with the nebuliser held 1-2 fingerbreadths from the open mouth, subjects were instructed to inhale slowly from functional residual capacity towards total lung capacity over 2-3 seconds. The technician triggered the dosimeter at the onset of each inhalation. After holding the breath for 1-2 seconds the subject exhaled normally. Five inhalations constituted one dose of test solution. FEV was measured 30 and 90 seconds after each dose with a wedge spirometer (Vitalograph, Buckingham, UK). Five doses of normal saline were delivered, followed by increasing doses of methacholine (table 2) until the $\mathrm{FEV}_{1}$ decreased by $50 \%$ of the post saline values, or until the total cumulative nebulised dose of $210 \mu \mathrm{mol}$ had been delivered to the mouth.
Tidal breathing method

Solutions were delivered from a Wright nebuliser, containing $3 \mathrm{ml}$ of solution, driven by continuous air flow at $7 \cdot 5 \mathrm{l} / \mathrm{min}$. The mean (SD) outputs of two nebulisers were determined by weighing each nebuliser before and after two minute nebulisations without a subject on 10 occasions and were $0 \cdot 145(0.005)$ and $0.140(0.010) \mathrm{ml} / \mathrm{min}$. The same nebuliser was used for all solutions in a given test. Using a noseclip and with a mask held loosely over the nose and mouth, subjects inhaled aerosol by tidal breathing for two minutes per dose. $\mathrm{FEV}_{1}$ was measured 30, 90, and 180 seconds after each dose. Three doses of normal saline, followed by doubling concentrations of methacholine $(0.03-256 \mathrm{mg} / \mathrm{ml})$ were delivered until the $\mathrm{FEV}_{1}$ decreased by $50 \%$ of the baseline value, or until the total cumulative dose of $730 \mu \mathrm{mol}$ had been nebulised.

\section{Analysis of dose-response curves}

"Baseline $\mathrm{FEV}_{1}$ " was calculated as the mean $\mathrm{FEV}_{1}$ of all the post saline values (10 values for the dosimeter method; nine values for the tidal breathing method). Dose-response curves were generated by plotting the percentage change in $\mathrm{FEV}_{1}$ (lowest value after each dose) from the baseline $\mathrm{FEV}_{1}$ against the

Table 2 Dosimeter method: methacholine dose schedule

\begin{tabular}{llcc}
\hline $\begin{array}{l}\text { Concentration } \\
(\mathrm{mg} / \mathrm{ml})\end{array}$ & No. puffs & $\begin{array}{l}\text { Dose } \\
(\mu \mathrm{mol})\end{array}$ & $\begin{array}{l}\text { Cumulative dose } \\
(\mu \mathrm{mol})\end{array}$ \\
\hline 0.05 & 1 & 0.04 & 0.04 \\
0.05 & 1 & 0.04 & 0.08 \\
0.05 & 2 & 0.08 & 0.16 \\
0.05 & 5 & 0.20 & 0.36 \\
2.0 & 5 & 0.70 & 1.06 \\
5.0 & 5 & 1.8 & 2.9 \\
10.0 & 5 & 3.6 & 6.5 \\
25.0 & 5 & 9.0 & 15.5 \\
50.0 & 5 & 17.9 & 33.4 \\
100.0 & 5 & 35.5 & 69.0 \\
100.0 & 5 & 71.0 & 140.0 \\
100.0 & 5 & 71.0 & 210.0 \\
\hline
\end{tabular}

$\star$ Nebuliser output $=0.014 \mathrm{ml} /$ puff. 
$\log _{10}$ cumulative, nebulised dose of methacholine. A plateau response was considered present if there was less than a 5\% change in $\mathrm{FEV}_{1}$ over two or more of the final doses. The plateau was calculated as the mean of all values from the first of these dose steps and was expressed as the percentage change in $\mathrm{FEV}_{1}$ from the baseline $\mathrm{FEV}_{1}$. In 22 doseresponse curves the change in $\mathrm{FEV}_{1}$ was never more than $5 \%$ for each dose. For these curves the plateau was calculated as the mean of all values from the first dose at which the change in $\mathrm{FEV}_{1}$ was zero or decreased. The provocative dose causing a decrease in $\mathrm{FEV}_{1}$ of $10 \%\left(\mathrm{PD}_{10}\right)$ from the baseline was calculated by linear interpolation of two adjacent points on the cumulative log dose-response curves.

\section{STATISTICAL ANALYSIS}

The effect of the order of testing was examined in each subject. Since plateau responses did not always occur in all subjects (see below), the results of order analysis are given for the 12 subjects in whom a plateau response was measurable on all occasions. For baseline $\mathrm{FEV}_{1}$ and plateau the results of both methods (tidal breathing and dosimeter) were grouped and differences between days 1 , 2,3 , and 4 were examined with the general linear models procedure of the SAS statistical package. ${ }^{9}$ Examination of each method separately did not affect the result statistically. For $\mathrm{PD}_{10}$ the tidal breathing and dosimeter methods were examined separately in the same 12 subjects, since dose was calculated as the nebulised dose and is not directly comparable between methods. In subjects in whom there was less than a $10 \%$ change in baseline $\mathrm{FEV}_{1}$, the maximal cumulative doses of $210 \mu \mathrm{mol}$ or $730 \mu \mathrm{mol}$ were used in testing for the effect of order. This would tend to underestimate differences between days. Paired $t$ tests were used to test differences between the initial and subsequent tests under two circumstances: (1) when the initial test (with a given method) was on day 1 ; and (2) when the initial test was on days 2 or 3 . For the dosimeter method paired $t$ tests were also used to examine differences between day 1 and day 7, and between days 2,3 , or 4 and day 7 .

The within subject repeatability of the level of the plateau measured by each method and the agreement between the two methods were analysed by the method described by Bland and Altman. ${ }^{1011}$ All analyses of PD $_{10}$ were performed on logarithmically transformed data (base 10). The repeatability of each method was assessed from the mean $(x)$ and standard deviation (SD) of individual differences between replicates, and the within subject standard deviation $(\sigma r)$. Where $\left(x_{1}-x_{2}\right)$ was the difference between replicates by a given method, the formulae were:

$$
\begin{aligned}
\mathrm{SD} & =\sqrt{ }\left(\sum_{n}\left(x_{1}-x_{2}\right)^{2} / n\right) \\
\sigma r & =\sqrt{ }\left(\Sigma_{n}\left(x_{1}-x_{2}\right)^{2} / 2 n\right) \\
& =\mathrm{SD} / \sqrt{2}
\end{aligned}
$$

These two values provide $95 \%$ ranges which have different implications. The 95\% range based on $\pm 2 \mathrm{SD}$ values represents the range for change from one test to the next. The $95 \%$ range based on \pm 2 or represents the interval within which $95 \%$ of the differences between a single determination and that individual's true mean measurement will lie. The $95 \%$ ranges were corrected for sample size by the $t$ distribution. ${ }^{12}$ Where SD (or $\sigma r$ ) was on a log scale, the $95 \%$ ranges were calculated by antilog transformation.

Independence of repeatability from the size of the measurements was assessed by plotting the absolute value of individual differences between replicates against the individual means of the replicates, and comparing the correlation coefficient $(r)$ with the null hypothesis of $r=0$.

Agreement between methods was assessed by analysing the individual differences between the means of replicates for each method. The mean $(x)$ of the differences between each method was the bias. A paired $t$ test examined the hypothesis of zero bias. Since the SD of the differences is underestimated when replicates are averaged, the corrected SD $\left(\mathrm{SD}_{\mathrm{c}}\right)$ was: $\sqrt{ }\left(\mathrm{SD}^{2}+1 / 4 \mathrm{~S}_{\mathrm{D}}{ }^{2}+\right.$ $1 / 4 S_{\mathrm{T}}{ }^{2}$ ), where $S_{\mathrm{D}}$ and $S_{\mathrm{T}}$ are the $S \mathrm{D}$ values of differences between replicates for the dosimeter and tidal breathing methods respectively. Limits of agreement were estimated as $x \pm 2 \mathrm{SD}_{\mathrm{c}}$. Independence of agreement between methods from the size of the measurements was assessed by plotting the individual differences between the means of replicates for each method against the individual averages of the means of the two methods, and comparing $r$ with the null hypothesis of $r=0$.

\section{Results}

A plateau was reached in all five tests in 12 subjects, and in all but the third dosimeter test in an additional two subjects (table 3 ). Replicates of the plateau response were available in all subjects for the first two dosimeter tests, and in 14 subjects for the tidal breathing tests. One subject (no. 8) stopped one test because of dyspnoea before a plateau was reached. In three subjects the $\mathrm{FEV}_{1}$ continued to change by more than $5 \%$ per dose step without reaching a plateau by the final dose of methacholine. Subject no. 6 , with current asthma, had a fall in $\mathrm{FEV}_{1}$ greater than $50 \%$ on one occasion. A PD 10 could be measured at least once for all subjects. There was a close inverse relationship between $\log \mathrm{PD}_{10}$ and the plateau response, $r=-0.95$, $\mathrm{p}<0.001$ for the first dosimeter test and $r=-0.77, \mathrm{p}<0.01$ for the first tidal breathing test (fig 1).

\section{REPEATABILITY}

The baseline $\mathrm{FEV}_{1}$ did not change significantly from day to day (fig 2). The order in which the tests were performed affected the $\mathrm{PD}_{10}$ and plateau response differently (fig 2). For each subject the plateau responses were not significantly different on any test day with either method. PD $_{10}$ was, however, signifi- 
Table 3 Individual methacholine test results

\begin{tabular}{|c|c|c|c|c|c|c|c|c|c|c|}
\hline \multirow{2}{*}{$\begin{array}{l}\text { Subject } \\
\text { no. }\end{array}$} & \multicolumn{5}{|c|}{ Plateau response (\% change in $F E V_{1}$ ) } & \multicolumn{5}{|c|}{$P D_{10}(\mu m o l)$} \\
\hline & $D 1$ & D2 & D3 & $T 1$ & $T 2$ & $D 1$ & D2 & D3 & $T 1$ & $T 2$ \\
\hline 1 & 17 & 14 & 14 & 9 & 8 & 17 & $67 \cdot 8$ & 103 & $>730$ & 470 \\
\hline 2 & 11 & 6 & 20 & 12 & 12 & $67 \cdot 8$ & $>210$ & 78 & 76 & 147 \\
\hline 3 & 40 & 43 & 50 & 44 & 30 & $1 \cdot 8$ & $3 \cdot 4$ & $<1 \cdot 8$ & 3.6 & $<2.9$ \\
\hline 4 & 19 & 13 & 18 & 29 & $28^{\star}$ & 50 & $84 \cdot 5$ & 52 & 126 & 216 \\
\hline 5 & 36 & 38 & 38 & 26 & 32 & $3 \cdot 8$ & $2 \cdot 8$ & $3 \cdot 6$ & 27 & 50 \\
\hline 6 & 46 & 35 & $54^{\star}$ & 37 & 26 & 0.7 & $2 \cdot 5$ & 0.8 & $<0.1$ & $28 \cdot 7$ \\
\hline 7 & 14 & 17 & 33 & 17 & 31 & $71 \cdot 5$ & $46 \cdot 2$ & $14 \cdot 4$ & 118 & $29 \cdot 5$ \\
\hline 8 & 19 & 26 & $41^{\star \star}$ & 47 & 27 & 25 & $14 \cdot 4$ & $7 \cdot 3$ & $10 \cdot 8$ & 48 \\
\hline 9 & 12 & 7 & 6 & 9 & 8 & 139 & 210 & $>210$ & 730 & $>730$ \\
\hline 10 & 36 & 37 & 43 & 40 & 36 & $1 \cdot 8$ & $3 \cdot 8$ & $4 \cdot 2$ & 5 & $10 \cdot 6$ \\
\hline 11 & 16 & 10 & 21 & 17 & 7 & 103 & 86 & $32 \cdot 3$ & 24 & 280 \\
\hline 12 & 34 & 32 & 32 & 28 & 25 & $10 \cdot 2$ & $14 \cdot 4$ & $9 \cdot 4$ & 48 & 126 \\
\hline 13 & 6 & 7 & 10 & $34^{\star}$ & 9 & $>210$ & $>210$ & 103 & 100 & $>730$ \\
\hline 14 & 17 & 26 & 31 & 39 & 24 & $40 \cdot 2$ & $32 \cdot 3$ & $15 \cdot 4$ & $<2.9$ & 24 \\
\hline 15 & 9 & 4 & 2 & 9 & 4 & 139 & $>210$ & $>210$ & 38 & $>730$ \\
\hline 16 & 10 & 6 & 13 & 7 & 11 & 92 & $>210$ & 140 & $>730$ & 180 \\
\hline
\end{tabular}

D1, D2, D3-first, second and third dosimeter tests, respectively; T1, T2-first and second tidal breathing tests, respectively.

*Values are the maximal change in $\mathrm{FEV}_{1}$ which occurred in the absence of a plateau.

$\star \star$ Subject stopped before a plateau was reached.

cantly greater at any subsequent test (day 2 , 3 , or 4) compared with a test on day 1 , with both methods. $\mathrm{PD}_{10}$ was not significantly different between tests on days 2 and 3 , days 2 and 4 , or days 3 and 4 and, for the dosimeter method, when day 1 was compared with day 7. The repeatability of $\mathrm{PD}_{10}$ was therefore examined only for the dosimeter method, comparing day 1 with day 7 . The within sub-

Figure 1 Relationship between $\log P D_{10}$ and the plateau response at the first dosimeter test in 14 subjects (open squares, $r=-0.95$, $p<0.001)$ and at the first tidal breathing test in 11 subjects (closed squares, $r=-0 \cdot 77, p<0 \cdot 01$ ).

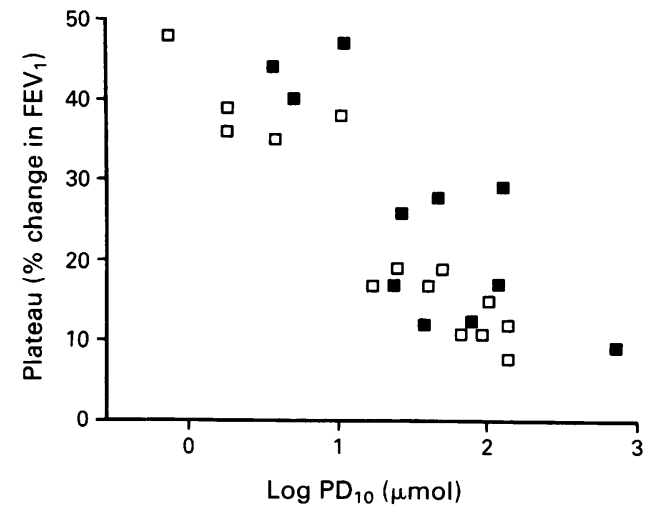

Figure 2 Effect of order of testing on baseline FEV, and dose-response curve characteristics. FEV, and plateau response did not change significantly after day 1 , whereas $P D_{10}$ was significantly greater at 24 hour intervals after the first test with both methods of delivery. After a further three days without testing (day 7) there was no significant difference in $P D_{10}$ measured by the dosimeter method compared with day $1 .{ }^{*} p<0.05$ compared with day 1.

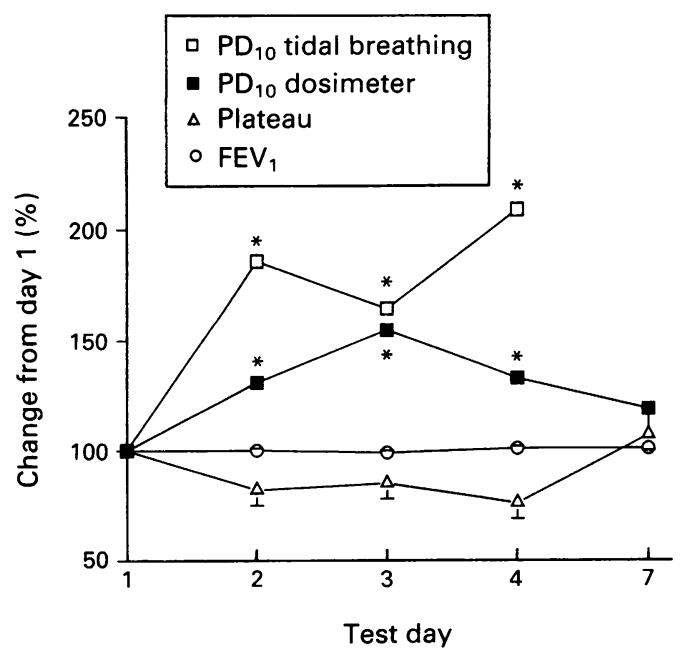

ject standard deviations of the plateau responses between the first and second dosimeter tests, the first and third dosimeter tests, and the first and second tidal breathing tests, and for $\mathrm{PD}_{10}$ between the first and third dosimeter tests, are shown in table 4. The $95 \%$ ranges for change from one test to the next, based upon $2 \mathrm{SD}$, were $\pm 11.9 \%$ (change in $\mathrm{FEV}_{1}$ ) $, \pm 19 \cdot 2 \%, \pm 20 \cdot 3 \%$, and a 7.9 fold change, respectively. The $95 \%$ ranges for a single determination in relation to an individual's mean value, based on $2 \sigma r$, were $\pm 8.3 \%$ (change in $\mathrm{FEV}_{1}$ ), $\pm 13.6 \%$, $\pm 14 \cdot 3 \%$, and a $5 \cdot 0$ fold change, respectively. Repeatability of the plateau response and the $\log \mathrm{PD}_{10}$ were independent of the size of the measurements for all comparisons.

\section{AGREEMENT}

There was no significant bias between methods in assessing the plateau response (mean difference $=-1.0 \%, p>0.4)$. The limits of agreement for the plateau response indicate that $95 \%$ of the measurements by the tidal breathing method ranged from $15 \cdot 2 \%$ below to $13.2 \%$ above those obtained by the dosimeter method. Agreement of the plateau response between methods was also independent of the size of the measurements.

\section{Discussion}

The results of this study show that the level of the plateau on the dose-response curve for inhaled methacholine did not change significantly over 48 hours or a week with two different methods of administering methacholine. For individual subjects, however, the repeatability of the plateau response was not high. The plateau was more repeatable by the dosimeter method over a short period (48 hours) with a difference between two estimates of the plateau response in one person of greater than $12 \%$ (change in $\mathrm{FEV}_{1}$ ) likely to be significant. With the tidal breathing method a difference of greater than $20 \%$ 
Table 4 Within subject repeatability of the dosimeter and tidal breathing methods

\begin{tabular}{|c|c|c|c|c|c|c|c|}
\hline \multirow[b]{2}{*}{ Test pairs } & \multicolumn{5}{|c|}{ Difference between two tests } & \multicolumn{2}{|c|}{$95 \%$ ranges for: } \\
\hline & $n$ & Mean & $p$ & $S D$ & $\sigma r$ & Change & $\begin{array}{l}\text { Single } \\
\text { determination }\end{array}$ \\
\hline \multicolumn{8}{|c|}{ Plateau response $(\%)$} \\
\hline $\mathrm{D} 1-\mathrm{D} 2$ & 16 & $1 \cdot 0$ & $>0.5$ & $5 \cdot 6$ & $3 \cdot 9$ & \pm 11.9 & $\pm 8 \cdot 3$ \\
\hline $\mathrm{D} 1-\mathrm{D} 3$ & 14 & $3 \cdot 6$ & $>0 \cdot 1$ & $8 \cdot 9$ & $6 \cdot 3$ & $\pm 19 \cdot 2$ & $\pm 13 \cdot 6$ \\
\hline $\mathrm{T} 1-\mathrm{T} 2$ & 14 & $4 \cdot 4$ & $>0 \cdot 1$ & $9 \cdot 4$ & $6 \cdot 6$ & $\pm 20 \cdot 3$ & $\pm 14 \cdot 3$ \\
\hline \multicolumn{8}{|l|}{$\log \mathrm{PD}_{10}$} \\
\hline D1-D3 & 11 & 0.02 & $>0.9$ & 0.42 & $0 \cdot 30$ & $7 \cdot 94^{\star}$ & $5 \cdot 0^{\star}$ \\
\hline
\end{tabular}

$\sigma r-$ within subject standard deviation; D1-D2, D2-D3, T1-T2-differences between dosimeter (D) or tidal breathing (T) tests.

*Values have been transformed back to original units (that is, antilog values), and represent fold differences. response was not subject to tachyphylaxis. The results of this study suggest, however, that, although tachyphylaxis can shift the in vivo dose-response curve to the right, it does not reduce maximal airway narrowing. The factors that normally limit airway narrowing and determine the level of the plateau response include those limiting stimulation of smooth muscle, local neurohumoral influences, and the structural relationships between the airway wall tissues including smooth muscle and the surrounding elastic parenchyma. ${ }^{17}$ Many of these factors are unlikely to change over a short period of time.

There was no bias between methods in assessing the level of the plateau response, indicating that the methods were, on average, measuring the same property of the airways and suggesting that the measured plateau response was independent of the method of inhalation challenge testing used. Agreement between the two methods was, however, not high. This was probably partly because of the relatively less repeatable tidal breathing results, as agreement between methods is bound to be poor if either method is not repeatable.

This study confirms the inverse relationship between $\mathrm{PD}_{10}$ and the plateau response reported previously by Sterk et al. ${ }^{7}$ This association is likely to reflect the fact that both parameters are related to some common factor determining bronchial responsiveness. The observation of tachyphylaxis of the $\mathrm{PD}_{10}$, but not of the plateau response, shows that they can behave independently and this is supported by studies undertaken elsewhere. ${ }^{18-20}$

The usefulness of measurements of the maximal (plateau) response to inhaled bronchoconstricting agents remains to be determined. The maximal response may be a more useful predictor of symptom severity ${ }^{21}$ and a means of monitoring the efficacy of treatment. ${ }^{22}$ To be used in this manner, more information is needed on the stability of the maximal response in larger numbers of normal subjects and patients with mild asthma.

The authors wish to thank Mr Ming Lam for his help with statistical analysis. Altman ${ }^{1011}$ yields a coefficient of repeatabilit for the maximal plateau response of $\pm 7 \cdot 8 \%$-that is, a difference between two estimates of the plateau response of more than $8 \%$ change in $\mathrm{FEV}_{1}$ was likely to be significant. This is similar to the value of $12 \%$ we obtained for the dosimeter method but half the value for the tidal breathing method. Possible reasons for this discrepancy include differences in subject characteristics as mentioned above. Furthermore, in their calculations of the maximal response, Sterk et $\mathrm{al}^{7}$ included subjects who did not reach a plateau per se and substituted the absolute maximal change, whereas the present study excluded subjects from further analysis if replicates were not available.

In the present study the airway response, assessed by $\mathrm{PD}_{10}$, showed tachyphylaxis at intervals of 24 hours. This effect had disappeared after one week and the plateau

1 Cockroft DW, Killian DN, Mellon JJA, Hargreave FE. Bronchial reactivity to inhaled histamine: a method and clinical survey. Clin Allergy 1977;7:235-43.

2 Juniper EF, Frith PA, Dunnett C, Cockcroft DW, Hargreave FE. Reproducibility and comparison of responses to inhaled histamine and methacholine. Thorax 1978;33:705-10.

3 Chai H, Farr RS, Froehlich LA, Mathison DA, McLean JA, Rosenthal RR, et al. Standardization of bronchial inhalation challenge procedures. F Allergy Clin Immuno 1975;56:323-7.

4 Yan K, Salome C, Woolcock AJ. Rapid method for measurement of bronchial responsiveness. Thorax 1983;38. $760-5$.

5 Hargreave FE, Ryan G, Thomson NC, O'Byrne PM, Latimer $\mathrm{K}$, Juniper EF, et al. Bronchial responsiveness to histamine or methacholine in asthma: measurement and clinical significance. $f$ Allergy Clin Immunol 1981;68:347-55.

6 Woolcock AJ, Salome CM, Yan K. The shape of the doseresponse curve to histamine in asthmatic and normal subjects. Am Rev Respir Dis 1984;130:71-5.

7 Sterk PJ, Daniel EE, Zamel N, Hargreave FE. Limited 
bronchoconstriction to methacholine using partial flowvolume curves in nonasthmatic subjects. Am Rev Respir Dis $1985 ; 132: 272-7$.

8 Cherniack RM, Raber MB. Normal standards for ventilatory function using an automated wedge spirometer. $\mathrm{Am}$ Rev Respir Dis 1972;106:38-46.

9 SAS Institute. SAS/STATTM user's guide, release 6.03 edition. Cary, North Carolina: SAS Institute, 1988: 1028.

10 Altman DG, Bland JM. Measurement in medicine: the analysis of method comparison studies. Statistician 1983;32:307-17.

11 Bland JM, Altman DG. Statistical methods for assessing agreement between two methods of clinical measurement. Lancet 1986; ;:307-10.

12 Chinn S. Ranges, confidence intervals, and related quantities: what are they and when to use them? Thorax 1991;46:391-3.

13 Chinn S, Britton JR, Burney PGJ, Tattersfield AE, Papacosta AO. Estimation and repeatability of the response to inhaled histamine in a community survey. Thorax 1987;42:45-52.

14 Ryan G, Dolovich MB, Roberts RS, Frith PA, Juniper EF, Hargreave FE, et al. Standardization of inhalation provocation tests: two techniques of aerosol generation and inhalation compared. $\mathrm{Am}$ Rev Respir Dis 1981;123:195-9.
15 Balzano G, Carri ID, Gallo C, Cocco G, Melillo G. Intrasubject between-day variability of $\mathrm{PD}_{20}$ methacholine assessed by the dosimeter inhalation test. Chest 1989;95:1239-43.

16 Irwig LM, Simpson JM. Assessing agreement. Med $\mathcal{f}$ Aust 1989;151:235-6.

17 Moreno RH, Hogg JC, Pare PD. Mechanics of airway narrowing. Am Rev Respir Dis 1986;133:1171-80.

18 Guillemi S, James AL, Pare PD. Effect of breathing pattern during inhalation challenge on the shape and position of the dose-response curve. Lung 1989;167: 95-106.

19 Ding DJ, Martin JG, Macklem PT. Effects of lung volume on maximal methacholine-induced bronchoconstriction in normal humans. $\mathcal{F} A$ ppl Physiol 1987;63:1324-30.

20 Bel EH, Van Der Veen H, Kramps JA, Dijkman JH, Sterk PJ. Maximal airway narrowing to inhaled leukotriene D4 in normal subjects. Am Rev Respir Dis 1987, 136:979-84.

21 Sterk PJ, Bel EH. Bronchial hyperresponsiveness: the need for a distinction between hypersensitivity and excessive airway narrowing. Eur Respir ₹ 1989;2:267-74.

22 Bel EH, Van Der Veen H, Dijkman JH, Sterk PJ. The effect of inhaled budesonide on the maximal degree of airway narrowing to leukotriene D4 and methacholine in normal subjects in vivo. Am Rev Respir Dis 1989; 139:427-31. 